\title{
Effects of crocin on brain oxidative damage and aversive memory in a 6-OHDA model of Parkinson's disease
}

\author{
Efeitos da crocina no dano oxidativo cerebral e na memória aversiva em um modelo \\ 6-OHDA de doença de Parkinson
}

Rajaei $Z^{1,2}$, Hosseini M'1 , Alaei $H^{3}$

\begin{abstract}
The purpose of the present study was to investigate the effect of crocin on brain oxidative damage and memory deficits in a 6-hydroxydopamine (6-OHDA) model of Parkinson's disease. Male Wistar rats were subjected to unilateral injection of 6-OHDA (16 $\mu \mathrm{g})$ into the medial forebrain bundle and treated with crocin (30 and $60 \mathrm{mg} / \mathrm{kg}$ ) for six weeks. The rats were tested for memory performance at six weeks after 6-OHDA infusion, and then were killed for the estimation of biochemical parameters. The increase in thiobarbituric acid reactive substances (TBARS) and nitrite levels in the hippocampus were observed in the 6-OHDA lesioned rats, which was accompanied by memory deficits in a passive avoidance test at the end of week 6 . Moreover, treatment with crocin decreased TBARS and nitrite levels in the hippocampus, and improved aversive memory. The present study conclusively demonstrated that crocin acts as an antioxidant and anti-inflammatory agent in the hippocampus of parkinsonian rats and could improve aversive memory through its properties.
\end{abstract}

Keywords: Crocin; 6-hydroxydopamine; oxidative stress; nitric oxide; aversive memory; medial forebrain bundle.

RESUMO

O objetivo do presente estudo foi investigar o efeito da crocina no dano oxidativo cerebral e nos déficits de memória em um modelo 6-OHDA de doença de Parkinson. Ratos Wistar machos foram submetidos à injeção unilateral de 6-OHDA (16 $\mu$ g) em MFB e tratados com crocina (30 e 60 mg/kg), durante 6 semanas. Os ratos foram testados quanto ao desempenho da memória 6 semanas após a infusão de 6-OHDA, e, em seguida, foram sacrificados para a estimativa dos parâmetros bioquímicos. 0 aumento nos níveis de TBARS e de nitrito no hipocampo foram observados em ratos 6-OHDA lesionados, acompanhado por déficits de memória em um teste de esquiva passiva no final da semana 6. Além disso, o tratamento com crocina diminuiu os níveis de nitrito e de TBARS no hipocampo e melhorou a memória aversiva. 0 presente estudo demonstrou conclusivamente que a crocina age como um antioxidante e um agente anti-inflamatório no hipocampo de ratos parkinsonianos e pode melhorar a memória aversiva através de suas propriedades.

Palavras-chave: Crocin; 6-hidroxidopamina; estresse oxidativo; óxido nítrico; feixe medial do cérebro anterior.

Parkinson's disease (PD) is a progressive neurodegenerative disorder that is characterized by the degeneration of dopaminergic nigrostriatal neurons, which leads to motor symptoms of bradykinesia, rigidity, rest tremor, and postural imbalance ${ }^{1}$. Parkinson's disease also causes impairments in cognitive performance, and the progression of these deficits can lead to dementia². The hippocampus, which is involved in cognitive processes such as learning and memory, is implicated in memory deficits observed in PD since both structural and functional changes of the hippocampus have been observed in PD patients ${ }^{3,4}$. Several MRI studies have also clearly revealed that the reduction of hippocampal volume was accompanied by cognitive deficits in PD patients ${ }^{5}$.

Numerous studies have suggested that oxidative stress plays a major role in the pathogenesis of $\mathrm{PD}^{6}$. Free radicals and other reactive oxygen species (ROS) resulted from dopamine auto-oxidation and metabolism, lipid peroxidation, impaired mitochondrial function, and deficiencies in endogenous antioxidant systems that may all contribute

${ }^{1}$ Isfahan University of Medical Sciences, School of Medicine, Department of Physiology, Isfahan, Iran;

${ }^{2}$ Mashhad University of Medical Sciences, School of Medicine, Neurocognitive Research Center, Mashhad, Iran;

${ }^{3}$ Isfahan University of Medical Sciences, Alzahra Hospital, Isfahan Neurosciences Research Center, Isfahan, Iran.

Correspondence:Ziba Rajaei; Department of Physiology, School of Medicine, Isfahan University of Medical Sciences, Isfahan, Iran; E-mail: rajaeiz@med.mui.ac.ir Conflict of interest: There is no conflict of interest to declare.

Support: This study was supported by Isfahan University of Medical Sciences.

Received 16 March 2016; Received in final form 31 May 2016; Accepted 06 June 2016. 
to a progressive loss of dopaminergic neurons ${ }^{7,8}$. There is also some evidence showing that the neurotoxicity of 6-hydroxydopamine (6-OHDA), for the modeling of PD, is due to its oxidation and the formation of various oxidants and free radicals and the depletion of reduced glutathione ${ }^{9}$. This leads to lipid peroxidation, protein damage and ultimately degeneration of the nigrostriatal dopaminergic system. 6-OHDA has also been reported to produce reactive nitrogen species (RNS) such as nitric oxide (NO) by elevated expression of inducible nitric oxide synthase (iNOS), especially in neurons ${ }^{10}$. Reactive oxygen species can rapidly interact with NO and subsequently produce more powerful oxidant peroxynitrite. Peroxynitrite is known to structurally and functionally modify critical cellular macromolecules and cause oxidative damages, which finally leads to apoptotic cell death ${ }^{11}$.

Recently, the major focus of many preclinical studies is the identification of drugs or approaches that might prevent or inhibit the neurodegenerative process. In this context, it has been suggested that antioxidant molecules (carotenoids and polyphenols) and compounds interfering with production of reactive oxygen species and nitric oxide might be protective.

Crocin is a water- soluble carotenoid and an active constituent of saffron (Crocus sativus L.). It has been reported that crocin possesses multiple pharmacological properties, including antioxidative activity ${ }^{12,13}$, anti-inflammatory ${ }^{14}$, protection against cardiovascular diseases, inhibition of tumor cell proliferation, neuroprotection and protection of hepatocytes $^{12}$. It has also been shown that the spice saffron, which contains powerful antioxidants such as crocin, protects nigral and retinal dopaminergic cells in an acute MPTP mouse model of Parkinson's disease ${ }^{15}$. The antioxidant and radical scavenging activity of crocins have also been shown in several in vitro models ${ }^{12,16}$. Based on the role of oxidative and nitrosative stress on the pathophysiology of PD and considering the antioxidant and anti-inflammatory effects of crocin, the present study was designed to evaluate whether it protects against 6-OHDA-induced oxidative damage and memory deficits in rats.

\section{METHODS}

\section{Animals}

Adult male Wistar rats, weighing 250-300g were housed in an air conditioned colony room at $22^{\circ} \mathrm{C} \pm 2^{\circ} \mathrm{C}$ on a standard pellet diet and tap water ad libitum. The Ethics Committee for Animal Experiments at Isfahan University of Medical Sciences approved the study and all experiments were conducted in accordance with the National Institute of Health Guide for the Care and Use of Laboratory Animals (NIH Publications No 8023, revised 1996).

\section{Chemicals}

Crocin, 6-OHDA, and apomorphine hydrochloride were purchased from Sigma Aldrich Co. 2,2' Dinitro-5,5'-dithiodibenzoic acid (DTNB), trichloro acetic acid (TCA), 2-thiobarbituric acid (TBA), Tris-EDTA, chloral hydrate and hydrochloric acid (HCL) were obtained from Merck.

\section{Experimental design}

The animals were randomly divided into four groups, with eight rats in each group, as follows: normal saline sham-operated group, normal saline-treated lesioned group (6-OHDA), and the crocin-treated lesioned groups (crocin 30 and $60 \mathrm{mg} / \mathrm{kg} /$ day). Crocin was dissolved in normal saline and injected at doses of 30 and $60 \mathrm{mg} / \mathrm{kg} /$ day intraperitoneally, three days before the surgery for six weeks. The surgical procedures were carried out under general (chloral hydrate, $450 \mathrm{mg} / \mathrm{kg}$, ip) and local anaesthesia (lidocaine 2\%). The rats were placed in a stereotaxic apparatus and the lesion was induced by injection of 6-OHDA ( $16 \mu \mathrm{g} / 4 \mu \mathrm{l} 0.2 \%$ ascorbate saline) into the left medial forebrain bundle through microinjection pump (Kd Scientific, USA) according to the coordinates: AP: $-4.5 \mathrm{~mm}$; ML: $-1.7 \mathrm{~mm}$; DV: $-8.2 \mathrm{~mm}^{17}$. The rats of the sham-operated group also received an identical volume of the ascorbate saline as the vehicle. The injection rate was $1 \mu \mathrm{l} / \mathrm{min}$ and the needle was kept in place for an additional five minutes before slowly being retracted. At the end of the experiment, the animals were sacrificed and the hippocampus and cortex were dissected out, washed immediately in ice-cold saline, and homogenized in the $\mathrm{NaCl}$ solution by a homogenizer. The hippocampus and cortex were obtained bilaterally, and the data are measures from combined bilateral tissues.

\section{Lipid peroxidation levels}

The lipid peroxidation level of the hippocampus and cortex was measured as malondialdehyde, which is the end product of lipid peroxidation. The malondialdehyde reacts with TBA as a thiobarbituric acid reactive substance (TBARS) and produces a red colored complex that has a peak absorbance (A) at $535 \mathrm{~nm}$. Briefly, a mixture of TCA, TBA, and $\mathrm{HCl}$ were added to $1 \mathrm{~mL}$ of homogenate, and the mixture was heated for $45 \mathrm{~min}$ in a boiling water bath. After cooling, the samples were centrifuged at $1000 \times \mathrm{g}$ for $10 \mathrm{~min}$ and the absorbance was measured at $535 \mathrm{~nm}$. The level of TBARS was calculated according to follow equation ${ }^{13}$. Concentration $($ Molar $)=$ Absorbance $/ 1.65 \times 10^{5}$.

\section{Total thiol concentration}

Total sulfhydryl (SH) groups were measured using DTNB as the reagent. This reagent reacts with the SH groups to produce a yellow colored complex that has a peak absorbance at $412 \mathrm{~nm}$. Briefly, 1mL Tris-EDTA buffer $(\mathrm{pH}=8.6)$ was added to $50 \mu \mathrm{L}$ homogenate in $2 \mathrm{~mL}$ cuvettes and the sample absorbance was read at $412 \mathrm{~nm}$ 
against the Tris-EDTA buffer alone (A1). Then, $20 \mu \mathrm{L}$ of the DTNB reagent (10 $\mathrm{mM}$ in methanol) was added to the mixture and after $15 \mathrm{~min}$, the sample absorbance was read again (A2). The absorbance of the DTNB reagent was also read as a blank (B). The total thiol concentration $(\mathrm{mM})$ was calculated by: The total thiol concentration $(\mathrm{mM})=(\mathrm{A} 2-\mathrm{A} 1-\mathrm{B}) \times 1.07 / 0.05 \times 13.6^{13}$.

\section{Glutathion peroxidase assay}

GSH peroxidase concentration was measured with the GSH peroxidase kit (Randox Labs, Crumlin, UK).

\section{Nitrite levels}

The level of nitrite was measured using a colorimetric assay kit (Promega Corporation, USA) that involved the Griess reaction. Briefly, after adding sulphanilamide solution and incubation, $\mathrm{N}$-(1-naphthyl) ethylenediamine solution was added. Then, the sample absorbance was measured by a microreader in the wavelength of $492 \mathrm{~nm}$. The nitrite concentration of samples was determined by comparing comparison against with the nitrite standard reference curve.

\section{Passive avoidance learning}

The passive avoidance test was used in the current study, because it is a suitable model for evaluating hippocampal-dependent memory deficits in experimental animals. Passive avoidance learning was assessed by shuttle box at the end of week 6 . The apparatus consisted of a light compartment $(25 \times 25 \times 20 \mathrm{~cm})$ and a dark compartment $(50 \times 25 \times 20 \mathrm{~cm})$ with a grid floor and wooden walls. The two compartments were separated by a sliding guillotine door. On the day before training, each rat was placed into the apparatus and allowed to move around 5 min for five minutes for habituation. In the training session, animals were placed individually in the light compartment for one minute. After opening the door and entrance of the rat entering into the dark chamber, the door was closed and a $1 \mathrm{~mA}$ foot electric shock was delivered for $3 \mathrm{~s}$ through the grid floor. The current intensity for foot shock was selected based on previous studies in our laboratory. In the test session, each rat was again placed into the light compartment. The step-through latency to enter the dark compartment was measured as a positive index of memory performance, with a $300 \mathrm{~s}$ cut-off time ${ }^{18}$.

\section{Histology}

The animals were sacrificed by a high dose of the anaesthetic. Then, the brains were removed and stored in $10 \%$ formalin for $72 \mathrm{~h}$. The brains were sectioned coronally at $40 \mu \mathrm{m}$ by a freezing microtome (Leica, Germany). Sections were mounted on gelatin-coated slides and studied using a light microscope. The track of the needle and injection site of 6-OHDA (Figure 1) was determined by reference to a rat brain atlas ${ }^{17}$.

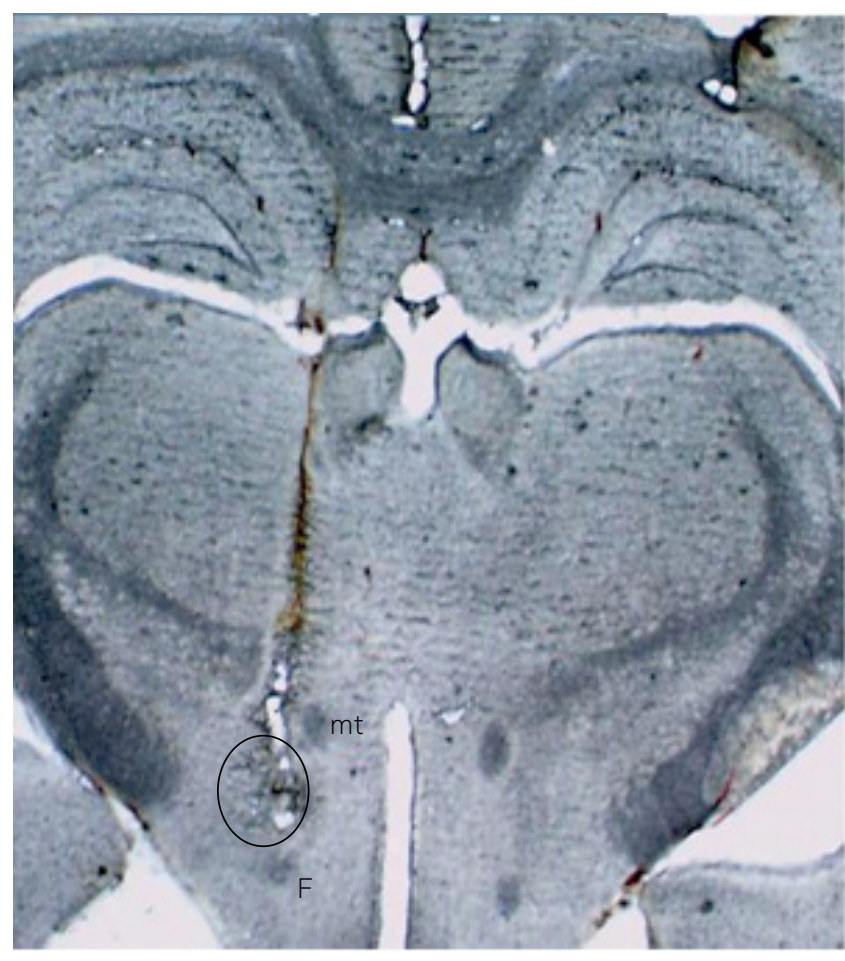

mt: mammilothalamic tract, F: fornix.

Figure 1. Photograph of the coronal section of rat brain representing injection site of 6-OHDA in the medial forebrain bundle (open circle).

\section{Statistical analysis}

The data were expressed as mean \pm SEM. Statistical analysis was carried out using one-way ANOVA followed by the LSD post hoc test. A statistical p-value $<0.05$ was considered significant.

\section{RESULTS}

\section{Effects of crocin on lipid peroxidation levels}

As shown in Figure 2, a significant increase in the levels of TBARS, an index of lipid peroxidation, was found in the hippocampus of 6-OHDA-lesioned rats $(\mathrm{p}=0.01)$ as compared with the sham group. Moreover, treatment of lesioned rats with crocin at a dose of $60 \mathrm{mg} / \mathrm{kg}$ reduced the TBARS levels in the hippocampus at the end of week $6(\mathrm{p}<0.05$, Figure 2$)$. Meanwhile, 6-OHDA increased the TBARS levels in the cortex of lesioned rats, although the changes were not significant.

\section{Effects of crocin on nitrite levels}

Figure 3 shows the nitrite levels in the hippocampus and cortex of the sham and experimental groups. A significant increase in the nitrite levels in the hippocampus $(\mathrm{p}<0.05)$ of 6-OHDA-lesioned rats was observed as when compared with sham group rats. Treatment of 6-OHDA-lesioned rats with crocin at a dose of $30 \mathrm{mg} / \mathrm{kg}$ significantly decreased the nitrite levels in the hippocampus as when compared to with the lesioned group ( $<<0.05$, Figure 3 ). Meanwhile, 6-OHDA 
did not change the nitrite levels in the cortex of lesioned rats compared with sham group rats (Figure 3).

\section{Effects of crocin on total thiol concentration}

Figure 4 shows the total thiol concentration in the hippocampus and cortex of the sham and experimental groups. There was no significant change in total thiol concentrations in the hippocampus and cortex of sham and experimental groups (Figure 4).

\section{Effects of crocin on glutathione peroxidase levels}

As shown in Figure 5, there was no significant difference in glutathione peroxidase concentration in the hippocampus and cortex of sham, 6-OHDA-lesioned rats and lesioned groups treated with crocin at 30 and $60 \mathrm{mg} / \mathrm{kg}$ at the end of week 6.

\section{Effects of crocin on passive avoidance learning}

As shown in Figure 6, the step-through latency of 6-OHDA-lesioned rats was shorter than the sham group rats at the end of week 6 ( $p<0.05$, Figure 6). Moreover, treatment of lesioned rats with crocin at a dose of $30 \mathrm{mg} / \mathrm{kg}$ increased the latency as compared with lesioned rats $(\mathrm{p}<0.05)$.

\section{DISCUSSION}

In the present study, we evaluated the effect of crocin on biochemical and behavioral parameters using the 6-OHDA rat model, because this model imitates the pathological and biochemical features of PD, such as oxidative stress, mitochondrial dysfunction and apoptosis ${ }^{19}$. Oxidative stress, imbalance of free radicals and antioxidants, plays a critical role in the pathogenesis of PD. Dopaminergic neurons are particularly sensitive to oxidative stress because of their low antioxidant capacity, as evidenced by low intracellular glutathione ${ }^{20}$. A number of studies have also demonstrated that the neurotoxicity of 6-OHDA for the modeling of PD is due to its oxidation, the formation of various oxidants and free radicals and the depletion of reduced glutathione, which leads to lipid peroxidation, protein damage and
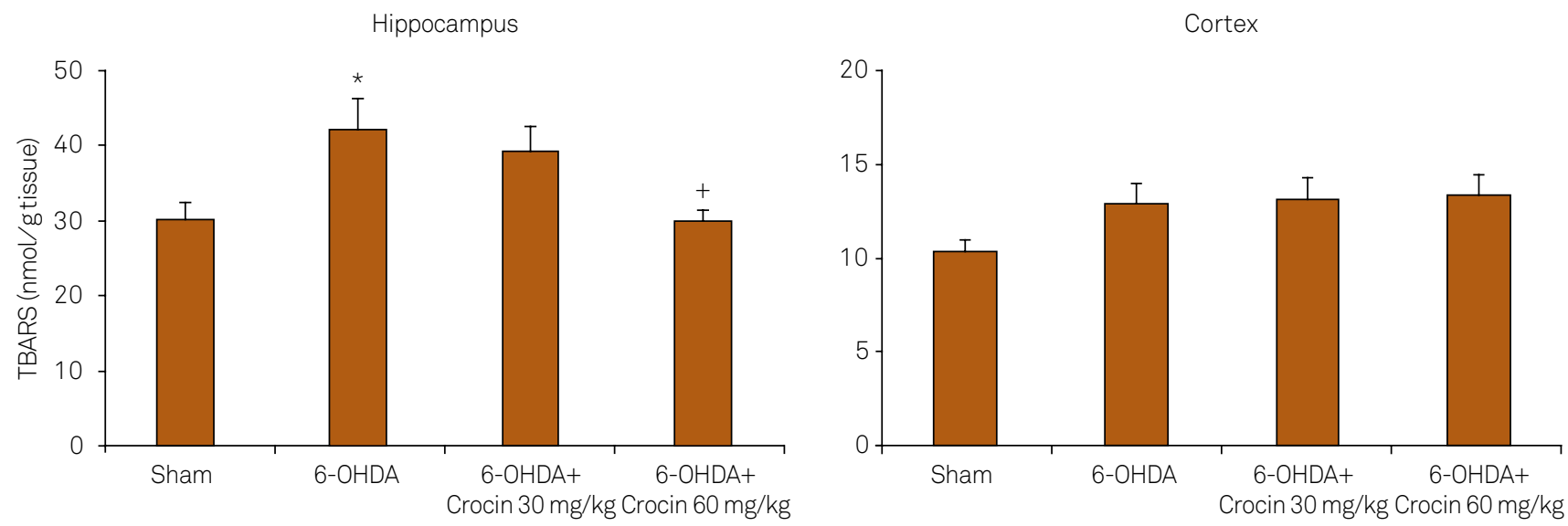

Figure 2. Lipid peroxidation levels (thiobarbituric acid reactive substance [TBARS]) in the hippocampus and cortex of the sham, 6-OHDA-lesioned rats and lesioned rats treated with crocin at doses of 30 and $60 \mathrm{mg} / \mathrm{kg}$ at the end of week 6 . Data are mean \pm SEM for eight animals in each group. ${ }^{*} p=0.01$ vs sham group, $+p<0.05$ vs 6 -OHDA-lesioned group.
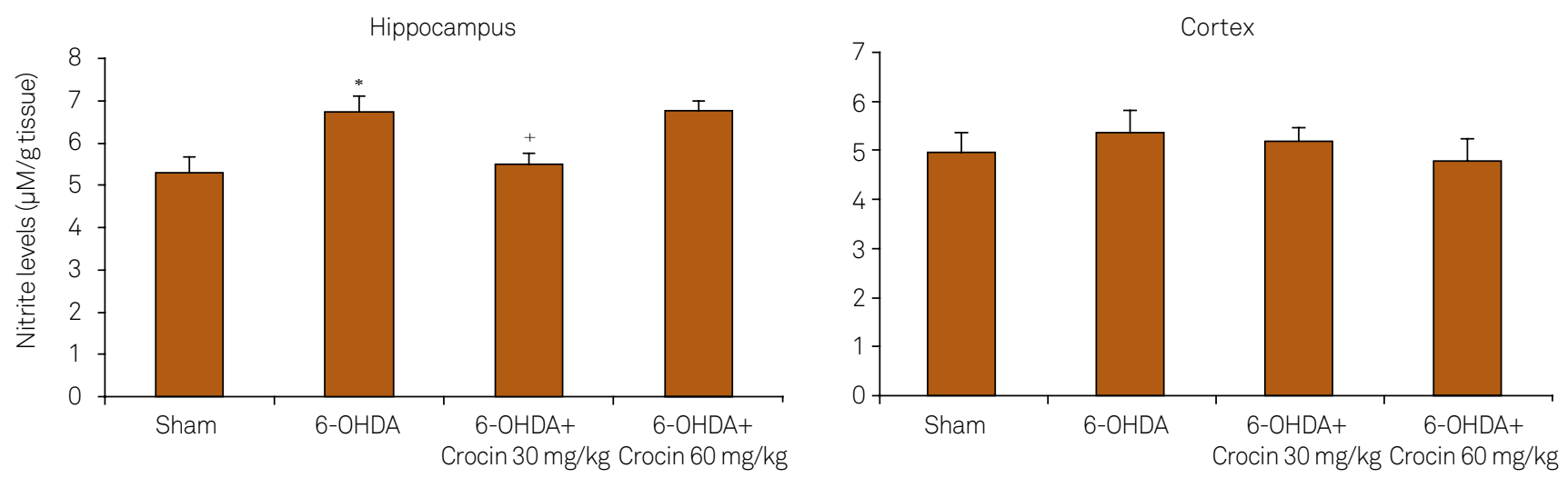

Figure 3. Nitrite levels in the hippocampus and cortex of the sham, 6-OHDA-lesioned rats and lesioned rats treated with crocin

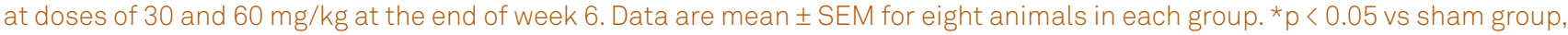
$+p<0.05$ vs $6-$ OHDA-lesioned group. 

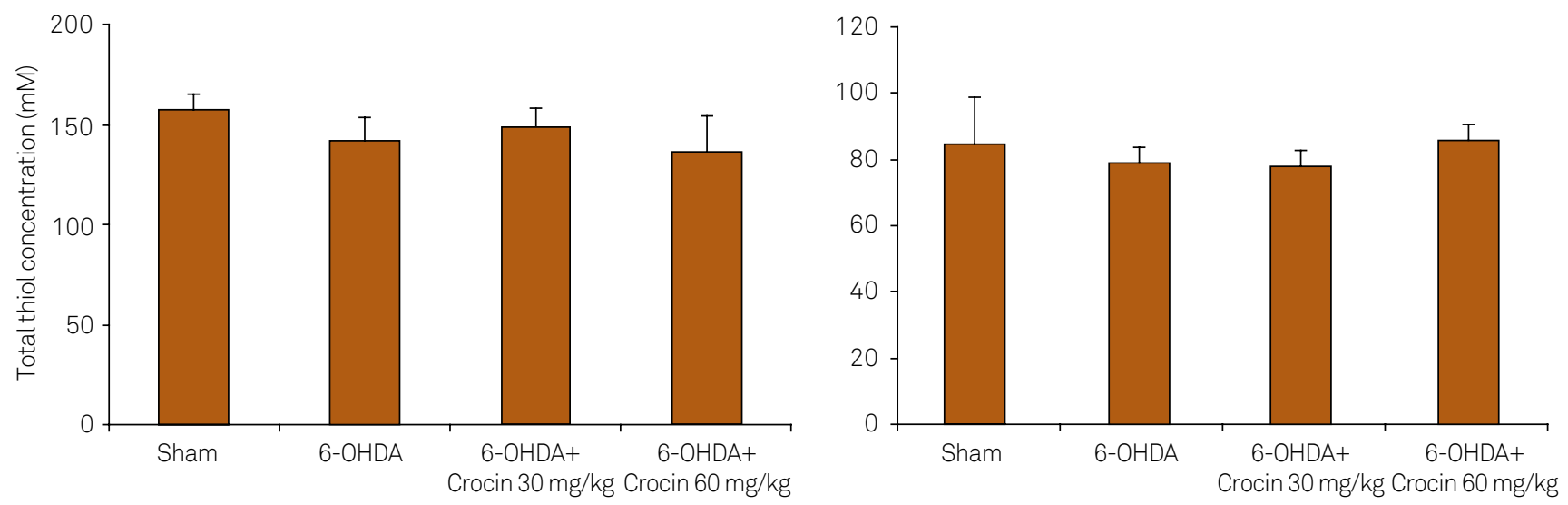

Figure 4. Total thiol concentrations in the hippocampus and cortex of the sham, 6-OHDA-lesioned rats and lesioned rats treated with crocin at doses of 30 and $60 \mathrm{mg} / \mathrm{kg}$ at the end of week 6 . Data are mean \pm SEM for eight animals in each group.
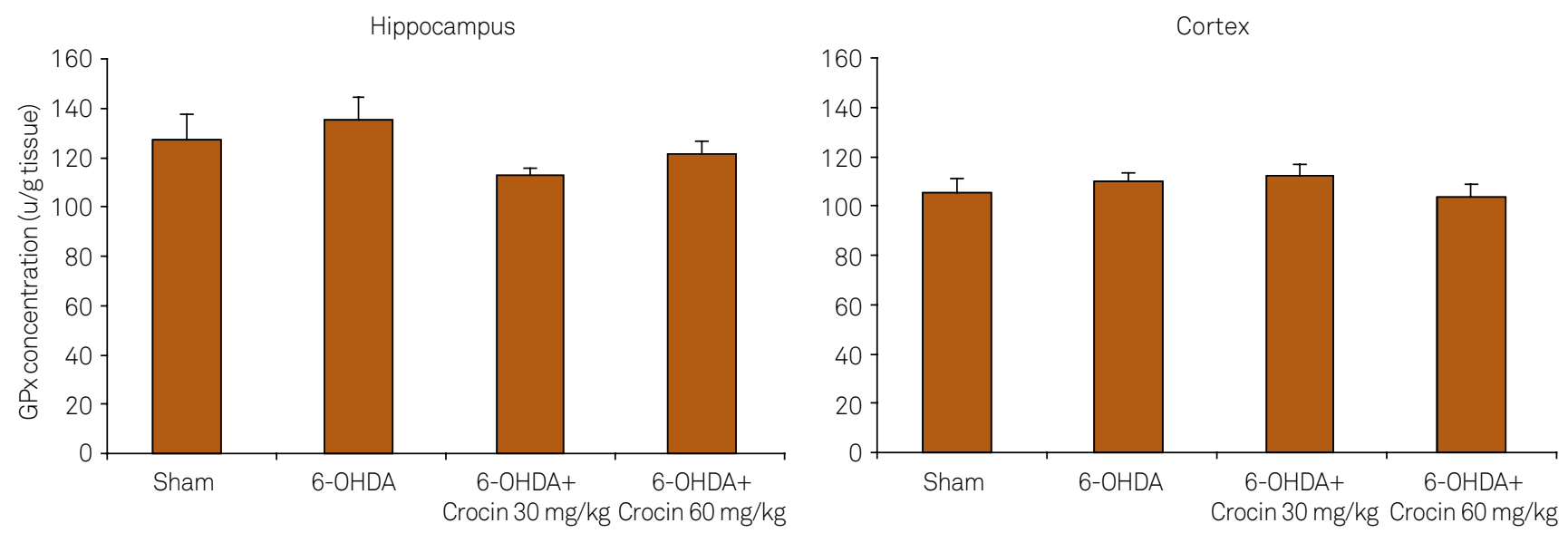

Figure 5. Glutathione peroxidase concentrations in the hippocampus and cortex of the sham, 6-OHDA-lesioned rats and lesioned rats treated with crocin at doses of 30 and $60 \mathrm{mg} / \mathrm{kg}$ at the end of week 6 . Data are mean \pm SEM for eight animals in each group.

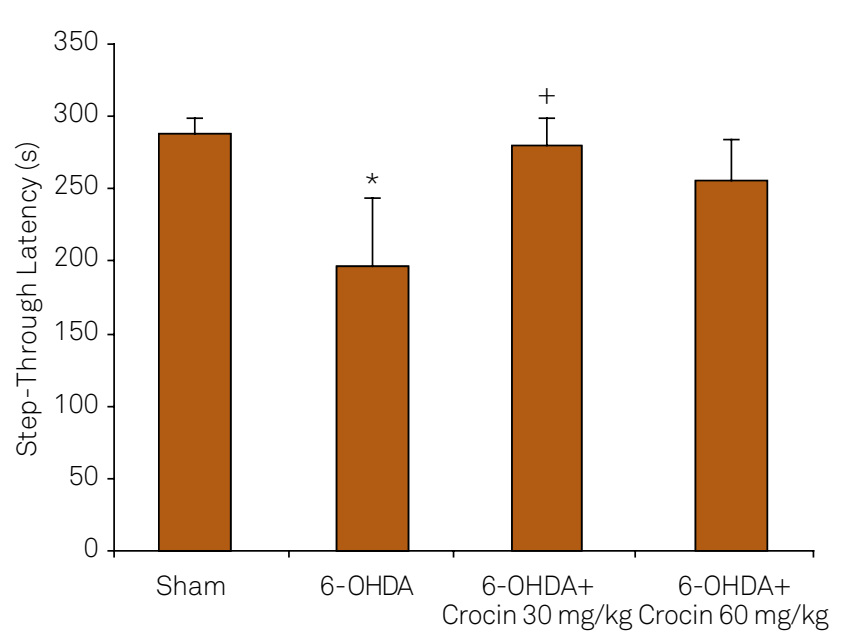

Figure 6. Step-through latencies in the passive avoidance test in the sham, 6-OHDA-lesioned rats and lesioned rats treated with crocin at doses of 30 and $60 \mathrm{mg} / \mathrm{kg}$ at the end of week 6 . Data are mean \pm SEM for eight animals in each group. ${ }^{*} p<0.05$ vs sham group, $+p<0.05$ vs $6-$ OHDA-lesioned group. ultimately degeneration of the neurons 9 . In the present study, we observed an elevated levels of TBARS in the hippocampus of PD rat brains, which was not accompanied by a depleted glutathione peroxidase level. This was, in part, in agreement with previous observations ${ }^{21}$. Our findings also revealed that long-term treatment with crocin reduced the TBARS levels in the hippocampus of parkinsonian rats. This is in agreement with previous studies which that report the antioxidant effects of crocin in other models. For example, Rajaei et al. ${ }^{13}$ reported that crocin attenuated hepatorenal oxidative damage in streptozotocin-induced diabetic rats, as indicated by a significant decrease in TBARS levels and an elevation in total thiol concentrations. Furthermore, the radical-scavenging and neuroprotective effects of crocins have also been shown in several in vitro models ${ }^{12,16}$. For instance, Zhang et al. ${ }^{16}$ have recently shown that crocin protects PC12 cells against 1-methyl-4-phenylpyridinium-induced injury. Collectively, it seems that the antioxidant activity of crocin in the hippocampus in a 6-OHDA model of PD is related to its antioxidant and radical scavenging activity. 
A large body of evidence also supports the involvement of inflammation in the pathogenesis of PD. Microglial activation is considered as a rapid cellular response to inflammation. Activation of microglia induces cytotoxic mediators such as NO and inflammatory cytokines, which may contribute to the PD progression ${ }^{22}$. NO production resulting from induced NOS gene expression and subsequent iNOS enzyme activation is a primary contributor to the inflammatory response ${ }^{22,23}$. Examination of postmortem PD brains has revealed robust microgliosis and the presence of high levels of iNOS expression in the substantia nigra (SN) compared with control brains ${ }^{24}$. It has also been reported that unilateral injection of 6-OHDA into the SNc increased NOS expression in the SN and striatum of PD rats $^{25}$. Along with this, the present findings showed that the 6-OHDA increased the levels of the nitrite, stable NO metabolite, in the hippocampus of parkinsonian rats. The results also showed that treatment with crocin attenuated the nitrite levels in this tissue. To our the best of knowledge, this is the first study reporting the anti-inflammatory effects of crocin through reducing NO levels in a 6-OHDA model of Parkinson's disease, which is in agreement with its anti-inflammatory effects that have previously been reported $^{14}$. In this context, it has been reported that crocin inhibited the lipopolysaccaride-induced NO release from cultured rat brain microglial cells ${ }^{14}$. Moreover, treatment with crocin decreased NO levels and NOS activity in cortical microvascular homogenates in an ischemic model in rat ${ }^{26}$.

In the present study, 6-OHDA injections also produced memory deficit, which acts by increasing oxidative stress within the brain of rats. Previous studies have also demonstrated that 6-OHDA could produce cognitive impairments in animals, and oxidative stress has been shown to play an important role in memory impairment ${ }^{27}$. Reactive oxygen species induced by 6-OHDA can react with biological target molecules and contribute to increased neuronal damage and death through protein oxidation, DNA damage, and peroxidation of membrane lipids. In our study, the passive avoidance test was used to examine whether crocin could improve memory of parkinsonian rats. This task is based on the motivation of passive avoidance from the fear of foot shock. Crocin at a dose of
$30 \mathrm{mg} / \mathrm{kg}$ increased the step-through latency during the testing session as when compared to parkinsonian rats, in the other words, it produced the amelioration of retention memory in parkinsonian rats. Consistent with this, memory-enhancing effects of crocin have previously been previously reported in other models, such as cerebral ischemia.

However, it looks like that $60 \mathrm{mg} / \mathrm{kg}$ crocin is more efficient in decreaseing TBARS in the hippocampus compared to the $30 \mathrm{mg} / \mathrm{kg}$ dose, but $60 \mathrm{mg} / \mathrm{kg}$ crocin did not significantly affect the behavior impairment. This discrepancy could be related to the fact that several other factors, rather other than reactive oxygen species and oxidative stress, are also involved in the development of cognitive impairments in PD. These factors include the imbalance in NO production and increased nitrosative stress ${ }^{28}$, dysfunction of the cholinergic system ${ }^{29}$, neuroinflammation and apoptosis ${ }^{30}$. For instance, Kuhad and Chopra ${ }^{28}$ have reported a significant increase in nitrite levels in the cortex and hippocampus of diabetic rats having with cognitive deficits. In our study, nitrite levels were also significantly increased in the hippocampus of parkinsonian rats. Excessive production of NO by increased iNOS expression leads to the formation of an extremely potent oxidizing agent, peroxynitrite (ONOO-), which causes neuronal death ${ }^{10}$. Peroxynitrite, which is formed by reaction between superoxide and NO, reacts with many biological target molecules and damages the neurons by oxidizing or nitrating proteins, lipids, and $\mathrm{DNA}^{11}$. In fact, the cell membrane has no significant barrier against diffusion of peroxynitrite into cells, thus allowing peroxynitrite to induce DNA damage and to mediate the activation of apoptosis pathways ${ }^{10}$. Taken together, the data presented here suggest that the improvement of memory by $30 \mathrm{mg} / \mathrm{kg}$ crocin might be mediated, at least in part, by decreased production of NO and inhibition of nitrosative stress in the hippocampus.

In conclusion, the present study demonstrated that the crocin acts as an antioxidant and anti-inflammatory agent in the hippocampus of parkinsonian rats and could improve aversive memory, at least in part, through reducing nitrite levels in the brain. Considering the safety of crocin in clinical trials, it might be used as an adjunct therapy for improvement of memory impairments in PD in the future.

\section{References}

1. Marsden CD. Parkinson's disease. Lancet. 1990; 335(8695):948-52. doi:10.1016/0140-6736(90)91006-V

2. Goetz CG, Emre M, Dubois B. Parkinson's disease dementia: definitions, guidelines, and research perspectives in diagnosis. Ann Neurol. 2008;64(Suppl 2):S81-92. doi:10.1002/ana.21455

3. Joelving FC, Billeskov R, Christensen JR, West M, Pakkenberg B. Hippocampal neuron and glial cell numbers in Parkinson's disease: a stereological study. Hippocampus. 2006;16(10):826-33. doi:10.1002/hipo.20212

4. Jokinen P, Brück A, Aalto S, Forsback S, Parkkola R, Rinne JO. Impaired cognitive performance in Parkinson's disease is related to caudate dopaminergic hypofunction and hippocampal atrophy. Parkinsonism Relat Disord. 2009;15(2):88-93. doi:10.1016/j.parkreldis.2008.03.005

5. Laakso MP, Partanen K, Riekkinen P, Lehtovirta M, Helkala EL, Hallikainen $M$ et al. Hippocampal volumes in Alzheimer's disease, Parkinson's disease with and without dementia, and in vascular dementia: an MRI study. Neurology. 1996;46(3):678-81. doi:10.1212/WNL.46.3.678

6. Bhat AH, Dar KB, Anees S, Zargar MA, Masood A, Sofi MA et al. Oxidative stress, mitochondrial dysfunction and neurodegenerative diseases; a mechanistic insight. Biomed Pharmacother. 2015;74:101-10. doi:10.1016/j.biopha.2015.07.025 
7. Cadet JL, Brannock C. Free radicals and the pathobiology of brain dopamine systems. Neurochem Int. 1998;32(2):117-31. doi:10.1016/S0197-0186(97)00031-4

8. Jenner P. Altered mitochondrial function, iron metabolism and glutathione levels in Parkinson's disease. Acta Neurol Scand Suppl. 1993;146:6-13.

9. Kumar R, Agarwal AK, Seth PK. Free radical-generated neurotoxicity of 6-hydroxydopamine. J Neurochem. 1995;64(4):1703-7. doi:10.1046/j.1471-4159.1995.64041703.x

10. Guo S, Bezard E, Zhao B, Yang X, Bezard E, Zhao B. Protective effect of green tea polyphenols on the SHSY5Y cells against 6-OHDA induced apoptosis through ROS-NO pathway. Free Radic Biol Med. 2005;39(5):682-95. doi:10.1016/j.freeradbiomed.2005.04.022

11. Liaudet L, Vassalli G, Pacher P. Role of peroxynitrite in the redox regulation of cell signal transduction pathways. Front Biosci (Landmark Ed). 2009;14(14):4809-14. doi:10.2741/3569

12. Chen Y, Zhang H, Tian X, Zhao C, Cai L, Liu Y et al. Antioxidant potential of crocins and ethanol extracts of Gardenia jasminoides Ellis and Crocus sativus L.: a relationship investigation between antioxidant activity and crocin contents. Food Chem. 2008;109(3):484-92. doi:10.1016/j.foodchem.2007.09.080

13. Rajaei Z, Hadjzadeh MA, Nemati H, Hosseini M, Ahmadi M, Shafiee S. Antihyperglycemic and antioxidant activity of crocin in streptozotocin-induced diabetic rats. J Med Food. 2013;16 206-10. doi:10.1089/jmf.2012.2407

14. Nam KN, Park YM, Jung HJ, Lee JY, Min BD, Park SU et al. Anti-inflammatory effects of crocin and crocetin in rat brain microglial cells. Eur J Pharmacol. 2010;648:110-6. doi:10.1016/j.ejphar.2010.09.003

15. Purushothuman S, Nandasena C, Peoples CL, El Massri N, Johnstone DM, Mitrofanis J et al. Saffron pre-treatment offers neuroprotection to nigral and retinal dopaminergic cells of MPTP-Treated mice. J Parkinsons Dis. 2013;3(1):77-83. doi:10.3233/JPD-130173

16. Zhang GF, Zhang Y, Zhao G. Crocin protects PC12 cells against $\mathrm{MPP}^{+}$-induced injury through inhibition of mitochondrial dysfunction and ER stress. Neurochem Int. 2015;89:101-10. doi:10.1016/j.neuint.2015.07.011

17. Paxinos $\mathrm{G}$, Watson $\mathrm{C}$. The rat brain in stereotaxic coordinates. 5th ed Amsterdam: Elsevier Academic; 2005.

18. Wang GW, Cai JX. Reversible disconnection of the hippocampal-prelimbic cortical circuit impairs spatial learning but not passive avoidance learning in rats. Neurobiol Learn Mem. 2008;90(2):365-73. doi:10.1016/j.nlm.2008.05.009
19. Ungerstedt U. 6-Hydroxy-dopamine induced degeneration of central monoamine neurons. Eur J Pharmacol. 1968;5(1):107-10. doi:10.1016/0014-2999(68)90164-7

20. Sian J, Dexter DT, Lees AJ, Daniel S, Jenner P, Marsden CD. Glutathione- related enzymes in brain in Parkinson's disease. Ann Neurol. 1994;36(3):356-61. doi:10.1002/ana.410360306

21. Khuwaja G, Khan MM, Ishrat T, Ahmad A, Raza SS, Ashafaq M et al. Neuroprotective effects of curcumin on 6-hydroxydopamineinduced Parkinsonism in rats: behavioral, neurochemical and immunohistochemical studies. Brain Res. 2011;1368:254-63. doi:10.1016/j.brainres.2010.10.023

22. Koprich JB, Reske-Nielsen C, Mithal P, Isacson O. Neuroinflammation mediated by IL-1 beta increases susceptibility of dopamine neurons to degeneration in an animal model of Parkinson's disease. J Neuroinflammation. 2008;5(1):8. doi:10.1186/1742-2094-5-8

23. Mogi M, Togari A, Tanaka K, Ogawa N, Ichinose H, Nagatsu T. Increase in level of tumor necrosis factor (TNF)-alpha in 6-hydroxydopaminelesioned striatum in rats without influence of systemic L-dopa on the TNF-alpha induction. Neurosci Lett. 1999;268(2):101-4. doi:10.1016/S0304-3940(99)00388-2

24. Knott C, Stern G, Wilkin GP. Inflammatory regulators in Parkinson's disease: iNOS, lipocortin1, and cyclooxygenases1 and 2. Mol Cell Neurosci. 2000;16(6):724-39. doi:10.1006/mcne.2000.0914

25. Xu R, Zhou Y, Fang X, Lu Y, Li J, Zhang J et al. The possible mechanism of Parkinson's disease progressive damage and the preventive effect of GM1 in the rat model induced by 6-hydroxydopamine. Brain Res. 2014;1592:73-81. doi:10.1016/j.brainres.2014.09.053

26. Zheng YQ, Liu JX, Wang JN, Xu L. Effects of crocin on reperfusioninduced oxidative/nitrative injury to cerebral microvessels after global cerebral ischemia. Brain Res. 2007;1138:86-94. doi:10.1016/j.brainres.2006.12.064

27. Hritcu L, Ciobica A, Artenie V. Effects of right-unilateral 6-hydroxydopamine infusion induced memory impairment and oxidative stress: relevance for Parkinson's disease. Cent Eur J Biol. 2008;3(3):250-7. doi:10.2478/s11535-008-0023-8

28. Kuhad A, Chopra K. Curcumin attenuates diabetic encephalopathy in rats: behavioral and biochemical evidences. Eur J Pharmacol. 2007;576(1-3):34-42. doi:10.1016/j.ejphar.2007.08.001

29. Perry EK, Curtis M, Dick DJ, Candy JM, Atack JR, Bloxham CA et al. Cholinergic correlates of cognitive impairment in Parkinson's disease: comparisons with Alzheimer's disease. J Neurol Neurosurg Psychiatry. 1985;48(5):413-21. doi:10.1136/jnnp.48.5.413

30. Tiwari V, Chopra K. Resveratrol abrogates alcohol-induced cognitive deficits by attenuating oxidative-nitrosative stress and inflammatory cascade in the adult rat brain. Neurochem Int. 2013;62(6):861-9. doi:10.1016/j.neuint.2013.02.012 